versidad, y una colección adicional de cédulas sueltas, publicada como Apéndice, cuyo fin es llenar omisiones del Cedulario original. Los documentos van precedidos por una Introducción y una Advertencia del doctor Lanning, más un Estudio por el profesor Valle. El volumen contiene, además, notas del compilador y los índices generales y alfabéticos que son de necesidad para facilitar la consulta.

$\mathrm{La}$ importancia de este libro como fuente informativa para el conocimiento de la historia de la Real y Pontificia Universidad de México es tan obvia, que todo comentario a este respecto saldría sobrando. Baste decir que las cédulas comprendidas en él abarcan el período que va de 1551 a 1816, es decir, la historia completa de aquella Institución. Sin embargo, no es éste el único motivo por el cual el libro tiene un interés muy subido. En efecto, a nadie se le ocultará que decir "historia de la antigua Universidad de México" es tanto como decir "historia de lo más saliente de la actividad cultural de la Colonia", de tal manera que el Cedulario es, además y no secundariamente, un índice de primer orden que nos permite asomarnos adecuada y auténticamente a las inquietudes espirituales de la Nueva España. Es ello tanto más cierto, cuanto que muchos de los documentos contenidos en el libro se refieren también a otras universidades y a diversos colegios y escuelas, no sólo en la ciudad de México, sino en otras ciudades del Virreinato. El libro desborda, pues, las limitaciones que a primera vista parece indicar su título general.

Como hijo y profesor de la Universidad Nacional de México, me es honroso terminar esta breve nota agradeciendo al doctor Lanning el grande servicio que le ha hecho a nuestra Casa de Estudios.

\title{
EDMUNDO O'GORMAN
}

Nuevos documentos relativos a los bienes de Hernán Cortés, 1547-1947.México, Imprenta Universitaria, 1946.

Con este título presenta el Archivo General de la Nación de México, el segundo de los tomos de la serie prometida en brillante labor de divulgación, a la cual se encuentra asociada la Universidad Nacional Autónoma de México.

La importancia de los documentos presentados a la consideración de los estudiosos, se funda no solamente en la referencia a la apasionante per- 
sonalidad de don Hernando y a la de personajes tan tristemente célebres como Juan Ortiz de Matienzo y Diego Delgadillo, los primeros oidores, sino además en definir la actuación digamos política de muchos de los conquistadores y pobladores reunidos en los catálogos de Orozco y Berra, Icaza y O'Gorman; demuestran los documentos la importancia que la corona de España concedía en la administración de su justicia a los testimonios indígenas, gracias al cuidado con que se recogen los memoriales en lengua original, evocadores de la dulce figura de Sahagún, en el expediente formado a petición del hijo legítimo de Cortés y que coadyuvan a redondear la idea que de la justicia se tenía, no solamente como derecho, sino como función social.

Los documentos publicados proceden del fondo del Hospital de Jesús, la institución cuya historia se halla tan ligada a la memoria de Cortés y que es el fondo más recientemente incorporado al Archivo General.

El libro se inicia con una Advertencia firmada por el doctor Julio Jiménez Rueda y la Introducción se debe al historiador encargado del estudio y anotación de los manuscritos, don Francisco González de Cossío.

El historiador dedica el primer capítulo al "Proceso del Marqués del Valle contra los licenciados Juan Ortiz de Matienzo e Diego Delgadillo, sobre los servicios e tributos del pueblo de Cuyuacán, fechado el 9 de febrero de 1531, motivado por el uso indebido de las rentas de la villa de Cuyuacán" propiedad de Cortés, hecha en su ausencia por Juan Ortiz de Matienzo y Diego Delgadillo.

El segundo capítulo lo integra el "Proceso del Marqués del Valle, contra los licenciados Juan Ortiz de Matienzo e Diego Delgadillo, sobre los servicios de Otumba e Tepeapulco", fechado también el 9 de febrero de 1531 , y motivado asimismo por el uso indebido que de los tributos propiedad del Marqués habían hecho ambos oidores durante su ausencia.

El tercer capítulo, o sea el "Proceso del Marqués del Valle, don Hernando Cortés, contra el fiscal licenciado Venavente sobre los pueblos de Totolapa e Atlatlahuca", es otro testimonio del odio que sentían los envidiosos de su riqueza.

El cuarto y último es la "Visita Tasación y cuenta de la Villa de Yecapixtla, Mor., a petición de don Martín Cortés, Marqués del Valle. Año de 1561".

El volumen termina con las notas, el índice onomástico y el índice general, cuidadosamente hechos. Con él se contribuye, dice el doctor Jiménez Rueda, como anticipo, a la conmemoración del cuarto centenario. de la muerte del Conquistador. 